\title{
Effectiveness of elective single versus double frozen embryo transfer in good prognosis in vitro fertilization patients
}

\author{
Tran Ha Lan Thanh 1,2, Pham Hoang Huy ${ }^{1,2}$, Do Thi Linh ${ }^{2,3}$, Nguyen Minh Tai Loc ${ }^{2}$, Nguyen Huu Duy ${ }^{2,3}$, \\ Dang Quang Vinh ${ }^{1,2}$, Nguyen Thi Thuong Huyen ${ }^{4, *}$ (i)
}

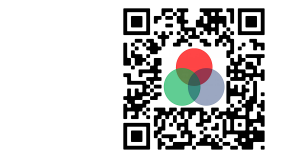

Use your smartphone to scan this QR code and download this article

${ }^{1}$ IVFMD Phu Nhuan, My Duc Phu Nhuan Hospital, Ho Chi Minh City, Viet Nam

${ }^{2}$ HOPE Research center, Ho Chi Minh City, Viet Nam

${ }^{3}$ IVFVH, Van Hanh General Hospital, Ho Chi Minh City, Viet Nam

${ }^{4}$ Department of Biology, Ho Chi Minh City University of Education, Viet Nam

Correspondence

Nguyen Thi Thuong Huyen, Department of Biology, Ho Chi Minh City University of Education, Viet Nam

Email: huyenntth@hcmue.edu.vn

History

- Received: Dec 04, 2020

- Accepted: Dec 28, 2020

- Published: Jan 30, 2021

DOI : 10.15419/bmrat.v8i1.658

\section{Check for updates}

\section{Copyright}

(c) Biomedpress. This is an openaccess article distributed under the terms of the Creative Commons Attribution 4.0 International license.

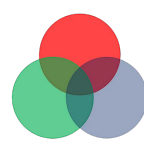

BioMedPress

The Open Access Publisher

\begin{abstract}
Objective: This study aimed to evaluate the effectiveness of elective single embryo transfer (eSET) versus double embryo transfer (DET) in frozen embryo transfer cycles following in vitro fertilization (IVF) treatment among good prognosis patients. The outcome was the provision of medical data focused on the multiple pregnancy rate reduction in IVF treatment. Methods: This multicenter retrospective cohort study was performed in patients undergoing their first frozen embryo transfer (FET) cycle at IVF centers belonging to the IVFMD Group in Vietnam from January 2018 to May 2020. The patients were divided into four groups based on the number of embryos transferred as follows: Group 1: one good quality day-3 embryo (eSET D3), Group 2: one good quality day-5 embryo (eSET D5), Group 3: two good quality day-3 embryos (DET D3), and Group 4: two good quality day-5 embryos (DET D5). The primary outcome of the study was the determination of the live birth rate (LBR) after the first FET. The secondary outcomes were also analyzed, including the pregnancy outcomes ( $\beta$-hCG positive, clinical pregnancy, miscarriage $<12$ weeks, ongoing pregnancy 12 weeks, miscarriage $<20$ weeks, and multiple birth rates [MBR]) and neonatal outcomes (birth weight and gestational age at birth). Results: There were 819 patients of which 819 FET cycles were analyzed, including 132 eSET D3, 278 eSET D5, 140 DET D3, and 269 DET D5. The values of LBR and MBR were significantly lower in the eSET D3 group than in the DET D3 group (LBR: $22.7 \%$ vs $39.3 \%, p=0.002$; MBR: $3.3 \%$ vs $29.1 \%, p<0.001$, respectively). MBR was also significantly lower in eSET D5 compared to DET D5 (9.6\% vs $38.3 \%, p<0.001)$, while LBR was comparable between the two groups ( $41.4 \%$ vs $42.8 \%, \mathrm{p}<0.74$ ). Birth weight and gestational age at birth were similar between ESET and DET regardless of whether it was in reference to day-3 or day- 5 embryo transfer. Conclusions: Among the infertile good prognosis women undergoing FET, the eSET significantly decreased the multiple birth rate compared with double embryo transfer while still sustaining an acceptable rate of live births as well as pregnancy and neonatal outcomes.
\end{abstract}

Key words: double embryo transfer, eSET, live birth rate, multiple birth rate, single embryo transfer

\section{INTRODUCTION}

The success of an in vitro fertilization (IVF) cycle is equal to achieving the birth of a healthy baby. Due to the advancements in IVF techniques and the improvements in the policies for embryo transfer, the live birth rate (LBR) has continuously improved since 1978. According to the United States (US) National Data from 1995 to 2013, the LBR in fresh embryo transfer cycles increased from $15 \%$ to $30 \%{ }^{1}$. In addition to the improvement of LBR, the status of multiple pregnancies commonly occurred following IVF treatment, accounting for about $31-41 \%$. This was higher than those following natural conception, totaling around 3.4\% according to the U.S. Centers for Disease Control and Prevention from 2013 to $2016^{2,3}$. Multiple pregnancies result in many consequences connected to both physical health and psychology for both the mother and child due to the higher risk of miscarriage, preterm birth, low birth weight, very low birth weight, and so on ${ }^{4,5}$. Therefore, it has been established as being necessary to ensure the safety of IVF treatment by controlling the multiple pregnancy rate. The main cause of multiple pregnancies following IVF treatment is the transfer of more than one embryo into the uterus ${ }^{6}$. Therefore, reducing the multiple pregnancy rate by decreasing the number of transferred embryos is one of the goals to achieve better efficacy and safety in IVF treatment. In recent years, many IVF centers all over the world have considered using eSET rather than DET in potential patients in order to reduce the multiple pregnancy rate $e^{7-13}$. eSET was first recommended in 2004 by the American Society for Reproductive Medicine (ASRM) and the Society for Assisted Reproductive Technology (SART) as an alternative to replace DET to reduce the multiple pregnancy rate in the transfer cycles of fresh embryos 
in good prognosis patient ${ }^{14}$. Good prognosis patients are typically defined as the following: maternal age < 35 years old, having their first IVF cycle or successful pregnancy during a previous IVF treatment, good quality embryos according to a morphological evaluation, and good quality embryos used in transfer or frozen ${ }^{14}$. According to the US national data, many IVF centers in the US have implemented eSET in patients $<38$ years of age to reduce the rate of multiple pregnancies but the cumulative live birth rate is not significantly different ${ }^{15}$. In 2017, ASRM/SART recommended that IVF centers should limit the number of transferred embryos depending on the embryo development stage and patient prognosis as part of frozen embryo transfer (FET) cycles. Using this guideline, SET was applied to good prognosis patients (maternal age $<38$ years old, having at least one good quality embryo, having euploid embryos, and having their first IVF treatment or a successful pregnancy during the previous treatment) ${ }^{11}$.

Furthermore, eSET was applied primarily to the blastocysts rather than the cleavage-stage embryos. This was because eSET results in a lower rate of clinical pregnancies and live birth rates at the cleavage-stage compared to the blastocyst stage ${ }^{16-18}$. Some studies have showed that eSET at the blastocyst stage reduced the multiple pregnancy rate from 10 to 20 -fold compared with DET. The results for both pregnancy and live births were not significantly different across the groups ${ }^{18-20}$. Moreover, birth weight following fresh blastocyst eSET was significantly different from DET in the younger patients ( $<35$ years old) $(3226.2$ $\mathrm{g} v s 2832.2 \mathrm{~g}, \mathrm{p}=0.001)^{19}$. Up until now, reports on the perinatal and neonatal outcomes of the eSET strategy have been very limited. In Vietnam, there have been many studies on the efficacy of various embryo transfer strategies. The randomized controlled trial (RCT) by Lan et al. (2018) compared the efficiency of frozen embryos versus fresh embryo transfers at My Duc Hospital. The results for the ongoing pregnancy and live birth rates were not significantly different between the frozen versus fresh embryo groups $(36.3 \%$ vs $34.5 \%$, RR $=1.05$, 95\% CI: 0.87 $-1.27, \mathrm{p}=0.65$, respectively, for the ongoing pregnancy group and $33.8 \%$ vs $31.5 \%, \mathrm{RR}=1.07,95 \% \mathrm{CI}$ : $0.88-1.31, \mathrm{p}=0.54$, respectively for the live birth rates group) ${ }^{21}$. According to another retrospective study in 2018, the findings showed that the cumulative live birth rate of day- 3 transferred embryos was no different to those transferred on day $-5^{22}$. A retrospective study by Phuong et al. (2019) was performed to compare the IVF outcomes following a single embryo transfer (SET) with or without pre-implantation genetic testing for aneuploidy (PGT-A) in advanced maternal age women. The study showed that PGTA can improve the ongoing pregnancy rate and reduce the number of transferred embryos and multiple pregnancy rates in patients of an advanced age ${ }^{23}$. Up until now, there have been no studies on the efficacy of SET. This can provide evidence-based information on the number of transferred embryos in Vietnamese IVF patients to improve the best IVF practices.

Currently, the strategy of elective single embryo transfer (eSET) is proposed for good prognosis patients to ensure a positive pregnancy outcome and to control the risk of multiple pregnancies in the IVF centers belonging to My Duc Hospital (IVFMD). This study was performed to evaluate the effectiveness of the eSET strategy compared with the double embryo transfer (DET) of cleavage-stage embryos or blastocysts.

\section{METHODS}

\section{Patient Selection and Study Design}

This research consisted of a multicenter retrospective cohort study performed on FET cycles at IVF centers belonging to IVFMD in Vietnam from January 2018 to May 2020. This study was approved by the Medical Ethics Committee of My Duc Hospital in Ho Chi Minh City, Vietnam (22.1/19/ĐĐ-BVMD). Any personal information was coded to ensure patient privacy.

Patients were included in this study if they met the following criteria: 35 years of age, 2 retrieved oocyte cycles, at least 4 grade- 1 or grade- 2 embryos on day 3 and having undergone FET with at least 1 grade1 or grade- 2 embryo on day 3 or day 5 . Patients undergoing in vitro maturation (IVM), oocyte donation, pre-implantation genetic testing (PGT), artificial oocyte activation (AOA), and/or with surgical sperm, uterine, or pelvic abnormalities were excluded. The patients were divided into four groups based on the number of embryos transferred: Group 1: one good quality day-3 embryo (eSET D3), Group 2: one good quality day-5 embryo (eSET D5), Group 3: two good quality day-3 embryos (DET D3), and Group 4: two good quality day-5 embryos (DET D5).

\section{Sperm Preparation}

Semen samples were collected by the method of masturbation directly into sterile containers that were left for 15 - 30 minutes to promote the liquefaction process. The samples were prepared using discontinuous density gradient centrifugation with a $40 \%$ density top layer and an $80 \%$ density lower layer $(40 \%$, $80 \%$ PureCeption-SAGE). The centrifugation lets the 
motile spermatozoa swim through the gradient materials to form a soft pellet at the bottom of the tube. The soft pellet was then collected and washed with 3 $\mathrm{ml}$ of Sperm Preparation medium (Origio, Denmark). The washed spermatozoa were concentrated in $0.2-$ $0.3 \mathrm{~mL}$ for use in an intracytoplasmic sperm injection $(\mathrm{ICSI})^{24}$.

Ovarian Stimulation and Oocyte Retrieval All of the patients underwent controlled ovarian hyperstimulation according to the protocol for the use of folliclestimulating hormones (FSH) and gonadotropinreleasing hormone antagonists. The dose of recombinant follicle-stimulating hormone was dependent on the woman's age, antimüllerian hormone levels $(\mathrm{AMH})$, and their response to FSH in any prior IVF cycle. Follicular development was monitored using ultrasonography to determine whether their estradiol (E2) and progesterone (P4) levels were evaluated. When the mean diameter of at least two leading follicles was $17 \mathrm{~mm}$, recombinant human chorionic gonadotropin (hCG) or diphereline was administered to trigger oocyte maturation. Oocyte retrieval was performed 36 hours later.

\section{Embryo Culture}

The oocytes were denuded from cumulus cells using hyaluronidase (SAGE, Denmark) in combination with the mechanical force of the pipette. The mature oocytes (metaphase II) were injected with sperm using ICSI 39 - 41 hours after hCG injection. After ICSI, the oocytes were incubated at $37^{\circ} \mathrm{C}, 5 \% \mathrm{CO}_{2}$ and $5 \%$ $\mathrm{O}_{2}$ until the time check for fertilization to determine if it was a cleavage-stage embryo (day 3 ) or blastocyst (day 5).

\section{Evaluation of Embryo Quality}

Fertilization was evaluated 16 - 18 hours after ICSI. The quality of the embryos was morphologically classified according to the guidelines of the IVFMD based on the Alpha Scoring System established in $2011^{25}$ ). Day-3 embryos were evaluated 66 - 68 hours postICSI based on the number of blastomeres, blastomere symmetry and fragmentation (\% ratio of fragment cells to embryo volume). Accordingly, a good grade 1 embryo contains 8 blastomeres of an equal size with fragmentation $\leq 10 \%$. There is also an absence of abnormal factors like vacuoles and blastomere multinucleation (MNB) (Figure 1 a). A grade 2 embryo typically contains 6 to 7 or more than 8 blastomeres of an unequal size and fragmentation $\leq 25 \%$ (Figure 1). Anything else is referred to as a grade 3 embryo. The blastocysts were evaluated 112 - 116 hours after ICSI (day 5) based on the expansion of the embryo cavity, the inner cell mass (ICM) characteristics, and the trophectoderm (TE) cell layer. Accordingly, good blastocysts (grade 1 and grade 2) - which had a full cavity-enlarged, compacted, large ICM - and many TE cells were assigned as the priority choices for transfer or freezing (Figure $1 \mathbf{c}, \mathbf{d}$ ).

\section{Embryo Cryopreservation}

The patients were consulted about the options for embryo freezing. All good embryos were proposed to be frozen. All embryos were frozen using the vitrification kit method (Cryotech, Japan). The frozen embryos were stored in liquid nitrogen $\left(-196^{\circ} \mathrm{C}\right)$.

\section{Frozen Embryo Transfer}

The patients underwent the process of endometrium preparation before the embryo transfer. The frozen embryos were thawed using a Warming Kit (Cryotech, Japan). The embryos were recorded in terms of quality and survival post-thawing. The thawed embryos were cultured in Global Total LP medium (LifeGlobal, US), and they were monitored throughout the steps of assisted hatching. The embryos were then transferred into the patient's uterus under ultrasound guidance.

\section{Determination of the Clinical Outcomes}

The primary outcome was LBR after the first frozen embryo transfer cycle. Live birth was defined as the birth of at least one newborn after a 24-week gestation that exhibits any signs of life.

The secondary outcomes were other pregnancy outcomes (beta-positive, clinical pregnancy, < 12-week miscarriage, 12-week ongoing pregnancy, $<20$ week miscarriage, multiple deliveries [ 2 babies]) and neonatal outcomes (birth weight and gestational age at birth). The clinical outcomes were monitored and recorded in the electronic medical record of each patient.

Serum beta-hCG level was measured 2 weeks after embryo transfer. If the beta-hCG was positive ( $\geq 25$ $\mathrm{IU} \mathrm{ml}$ ), a clinical pregnancy was confirmed at 6 weeks after embryo transfer through an ultrasonography of the gestational sac. An ongoing pregnancy was defined as a pregnancy with a detectable heartbeat after 12 weeks of gestation. Miscarriage $<12$ weeks or miscarriage $<20$ weeks were defined as complete clinical abortions at 12 -weeks or 20-weeks. Multiple births consisted of twins born with vital signs of life after a 24-week gestation. The birth weight and gestational age at birth were recorded. 


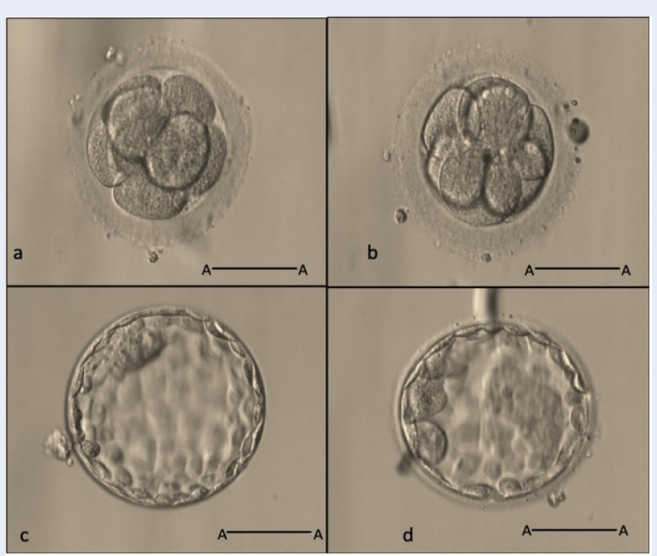

Figure 1: Day-3 embryos and day-5 embryos (20X, scale bar A-A: $50 \mu$ m). (a) Day-3 embryo grade 1, (b) Day-3 embryo grade 2, (c) Day-5 embryo grade 1, and (d) Day-5 embryo grade 2. https://doi.org/10.6084/m9.figshare.1 6573154.v1

\section{Statistical Analysis}

The baseline characteristics of the patients were described using descriptive statistics for both groups. The data was expressed as mean \pm standard deviation (SD) for the continuous variable and as a number (\%) for the binary variables. The P-values were estimated using the Student's t-test for the continuous variables and the Chi-square or Fisher's exact test for the binary variables. The factors affecting the live birth rates were evaluated using univariate logistic regression and multivariate logistic regression. All of the data in the study was processed using the statistical software R version 3.3.3 (R Foundation for Statistical Computing, Vienna, Austria).

\section{RESULTS}

From January 2018 to May 2020, there were 819 patients included in the study with a total of 819 FET cycles analyzed. This included 132 eSET D3, 278 eSET D5, 140 DET D3, and 269 DET D5. All of the baseline characteristics of the patients (eSET and DET group) were recorded including age, body mass index (BMI), $\mathrm{AMH}$, the duration of infertility, the type of infertility, the number of IVF cycles, and IVF indications. There were no statistically significant differences between the two groups $(p>0.05)$ (Table 1 ).

The clinical IVF characteristics and embryology outcomes of the two patient groups are shown in Table 2. The results show that the first dose of FSH and the trigger by hCG in the SET group of patients were both lower than the same in the DET group $(\mathrm{p}<0.05)$. The duration of the ovarian stimulation, serum progesterone (P4) and estrogen (E2) levels on the day of triggered oocyte maturation, the types of trigger (hCG or diphereline), the number of fertilized oocytes, the total number of embryos and the day-3 embryo rate in the SET group were significantly higher than the same in the DET group ( $\mathrm{p}<0.001$ ) (Table 2). Meanwhile, the total dose of FSH, endometrial thickness, the number of oocytes retrieved, the number of good day-3 embryos, and the total number of frozen embryos in the two groups were similar ( $p>0.05$ ).

The embryology and pregnancy outcomes were compared between eSET D3 and DET D3, as shown in Table 3. Pregnancy parameters such as $\beta$-hCG positivity, clinical pregnancy, and an ongoing pregnancy after a 12-week gestation in the DET group were all significantly higher than those in the eSET group ( $\mathrm{p}$ $<0.01$ ). In particular, LBR and MBR in the DET D3 group were significantly higher than in the eSET D3 group (39.3\% vs $22.7 \%, \mathrm{p}<0.01 ; 29.1 \%$ vs $3.3 \%$, $\mathrm{p}$ $<0.001$; respectively). However, the rate of implantation, miscarriage, ectopic pregnancy, and neonatal outcomes did not differ between the two groups ( $p$ $>0.05$ ). The results of the univariate logistic regression showed that the number of transferred embryos, the type of trigger, and the number of oocytes retrieved affected the live birth results post-day-3 embryo transfer (Supplemental Table 1). However, the results of the multivariate logistic regression showed that there was no correlation between the analyzed variables and live birth. The embryology and pregnancy outcomes in the eSET D5 and DET D5 groups are shown in Table 4. The results show that the implantation rate of eSET D5 was significantly higher than that of DET D5 $(54.3 \% \pm 57.3 \%$ vs $34.2 \% \pm$ $37.2 \%$; Absolute difference $=20.1,95 \%$ CI: 12.0, $28.2 \mathrm{p}$ $<0.001)$. Most pregnancy and neonatal outcomes did 
Table 1: The baseline characteristics of patients

\begin{tabular}{|c|c|c|c|}
\hline Characteristics & $\begin{array}{c}\text { eSET } \\
(\mathrm{N}=410)\end{array}$ & $\begin{array}{c}\text { DET } \\
(\mathrm{N}=409)\end{array}$ & P-value \\
\hline Age (years) & $29.8 \pm 3.1$ & $30.0 \pm 3.1$ & 0.20 \\
\hline BMI $\left(\mathrm{kg} / \mathrm{m}^{2}\right)$ & & $21.1 \pm 2.6$ & 0.60 \\
\hline $\mathrm{AMH}(\mathrm{ng} / \mathrm{ml})$ & $6.3 \pm 3.5$ & $6.2 \pm 3.8$ & 0.69 \\
\hline Duration of infertility (years) & $4.1 \pm 2.6$ & $4.0 \pm 2.6$ & 0.66 \\
\hline \multicolumn{4}{|l|}{ Type of infertility- n (\%) } \\
\hline Primary & $259(63.2)$ & $247(60.4)$ & 0.46 \\
\hline Secondary & $151(36.8)$ & $162(39.6)$ & \\
\hline \multicolumn{4}{|l|}{ Number of IVF cycles - $\mathrm{n}(\%)$} \\
\hline 1 & $343(83.7)$ & $341(83.4)$ & 0.99 \\
\hline 2 & $67(16.3)$ & $68(16.6)$ & \\
\hline \multicolumn{4}{|l|}{ IVF indication - $\mathrm{n}(\%)$} \\
\hline PCOS & $101(24.6)$ & $95(23.2)$ & - \\
\hline Ovulation disorder & $31(7.6)$ & $31(7.6)$ & - \\
\hline Tubal factor & $78(19.0)$ & $76(18.6)$ & - \\
\hline Diminished ovarian reserve & $5(1.2)$ & $14(3.4)$ & - \\
\hline IUI failure & $16(3.9)$ & $28(6.8)$ & - \\
\hline Male factor & $93(22.7)$ & $75(18.3)$ & - \\
\hline Other & $26(6.3)$ & $12(2.9)$ & - \\
\hline Unexplained & $60(14.6)$ & $78(19.1)$ & - \\
\hline
\end{tabular}

not differ between the two groups ( $p>0.05)$. Interestingly, MBR in the eSET D5 group decreased significantly compared to that of DET D5 (9.6\% vs 38.3\%, $\mathrm{p}<0.001$ ). eSET or DET with good quality embryos on day 5 , therefore this did not affect the pregnancy or neonatal outcomes, whereas eSET minimized MBR in these patients. The embryology and pregnancy outcomes between the eSET D3 and eSET D5 groups have been shown in Table 5. LBR in the eSET D3 group was significantly lower than it was for eSET D5 (22.7\% vs $41.4 \%, \mathrm{p}<0.001)$. Similarly, other embryology and pregnancy outcomes (such as $\beta$-hCG positivity, implantation, clinical pregnancy, and ongoing 12-week pregnancy) were significantly lower in the eSET D3 group ( $\mathrm{p}<0.001$ ). Meanwhile, the rates for miscarriage $<12$ weeks, ectopic pregnancy, MBR, and gestation age at birth did not differ between the two groups ( $p>0.05$ ). Furthermore, the birth weight of singletons in the eSET D3 group was significantly higher than that in the eSET D5 group (3086.7 $\mathrm{g} \pm 325.1 \mathrm{~g} v \mathrm{~s}$ $2859.1 \mathrm{~g} \pm 620.3 \mathrm{~g}, \mathrm{p}=0.01)$. However, this outcome was within the normal range $(2500-4000 \mathrm{~g})$ when referencing the WHO standards. The birth weight of twins was lower in the eSET D3 compared to the eSET D5 group. This is within the normal range. Good embryos from the eSET D3 group resulted in a significantly lower LBR compared to that of the eSET D5 group, but the MBR of the eSET D5 group was higher than that of eSET D3.

\section{DISCUSSION}

This is the first study on the effectiveness and safety of elective single frozen embryo transfer in Vietnam. The results of our study show that LBR following eSET D3 was significantly lower than that for DET D3 in FET cycles among good prognostic patients. Meanwhile, this rate was similar across the two groups of patients who transferred a day-5 embryo (eSET D5 and DET D5).

Moreover, it is necessary to ensure the maintenance of safety in IVF treatment by controlling for multiple pregnancies. Studies have recommended the implementation of eSET D3 and ESET D5 to reduce the multiple pregnancy rate ${ }^{15,18,26}$. In our study, eSET 
Table 2: Clinical IVF characteristics and embryology outcomes

\begin{tabular}{lccc}
\hline Characteristics & $\begin{array}{c}\text { eSET } \\
(\mathbf{N}=\mathbf{4 1 0})\end{array}$ & $\begin{array}{c}\text { DET } \\
(\mathbf{N}=\mathbf{4 0 9})\end{array}$ & P-value \\
\hline First dose of FSH (IU) & $219.9 \pm 52.0$ & $229.00 \pm 54.5$ & 0.02 \\
Duration of stimulation (days) & $9.1 \pm 1.2$ & $8.9 \pm 1.2$ & 0.04 \\
Total dose of FSH (IU) & $2309.4 \pm 687.1$ & $2344.3 \pm 664.1$ & 0.46 \\
E2 levels on day of trigger (pmol/l) & $16982.2 \pm 1682.5$ & $11621.2 \pm 1280.2$ & $<0.001$ \\
P4 levels on day of trigger (pmol/l) & $1.4 \pm 0.9$ & $1.2 \pm 0.8$ & 0.01 \\
Type of trigger - n (\%) & & & $<0.001$ \\
hCG & $80(19.5)$ & $190(46.5)$ & 0.15 \\
Diphereline & $330(80.5)$ & $219(53.5)$ & 0.35 \\
Endometrial thickness (mm) & $12.9 \pm 2.3$ & $12.5 \pm 2.2$ & $<0.001$ \\
No. of oocytes retrieved (n) & $16.8 \pm 7.2$ & $16.3 \pm 6.3$ & $<0.001$ \\
No. of two-pronuclear fertilized oocytes (n) & $15.8 \pm 7.2$ & $14.2 \pm 6.6$ & $<0.001$ \\
No. of day-3 embryos (n) & $15.0 \pm 7.4$ & $13.2(6.9)$ & 0.58 \\
Day-3 embryo rate (\%) & $93.2 \pm 15.6$ & $87.1 \pm 17.7$ & 0.26 \\
No. good day-3 embryos (n) & $8.4 \pm 3.6$ & $8.3 \pm 3.5$ & $5.6 \pm 3.5$ \\
Total no. of embryos frozen (n) & $5.9 \pm 4.2$ & $5(1.2)$ & \\
OHSS - n (\%) & $3(0.7)$ & & \\
\hline
\end{tabular}

also demonstrated its safety because this strategy reduced MBR by $11-12 \%$ compared to DET. Specifically, MBR was reduced by $11 \%$ in the eSET D3 group compared to DET D3 and by $12 \%$ in the eSET D5 group compared to DET D5. Similarly, the analysis of the data from 2004 to 2013 of the ASRM study (2017), conducted to examine the first fresh embryo transfer cycles in young patients ( $<35$ years old), showed that the LBR in eSET D3 decreased by $15 \%$ compared to that of DET D3, whereas eSET D5 decreased by $10 \%$ compared to DET D5. For eSET D5, the multiple pregnancy rate decreased by $22-47 \%$ compared to DET D5. For eSET D3, this rate decreased by $22-$ $28 \%$ compared to DET D3 in patients under 38 years old ${ }^{18}$. In contrast, the results of the largest sample size for a retrospective study were reported by Racca et al. (2020). They showed that the LBR between SET and DET were similar following either the cleavage embryo transfer ( $13.1 \%$ vs $14.8 \%, \mathrm{p}=0.33$, respectively) or the blastocyst transfer $(21.7 \%$ vs $23.4 \%, \mathrm{p}=0.4$, respectively). Multiple delivery rates were significantly higher in women with DET compared to SET (16.7\% vs $1.9 \% ; \mathrm{p}<0.001)^{27}$. The results of the multivariate logistic regression that were adjusted for the presence of confounding factors also showed that the number of embryos transferred in the FET cycle was not related to $\mathrm{LBR}^{27}$. Other studies showed that eSET D5 did not reduce the pregnancy and live birth rates compared to DET D5 ${ }^{15,28}$. According to the other study by Freeman et al. (2019), the LBRs between eSET D5 and DET D5 were found to be similar $(54-62 \% v s$ $54-66 \%, \mathrm{p}=0.696-1,000)$ and the MPR decreased significantly with eSET D5 compared to DET D5 (0$3 \%$ vs $24-65, \mathrm{p}<0.05)$ in good prognosis patients (under 38 years of age at oocyte collection, having at least two frozen blastocysts, and undergoing their first autologous FET cycle) ${ }^{29}$.

Our study showed that the neonatal outcomes, such as birth weight and gestational age at birth for eSET, did not differ when compared to those for DET after the day- 3 or day- 5 embryo transfer. However, birth weight for eSET D3 was significantly higher than that for eSET D5 ( $\mathrm{p}=0.01$ ) (Table 5). According to Friedman et al., the birth weight following eSET was significantly different compared to DET during the fresh blastocyst transfer cycles for patients $<35$ years old ${ }^{19}$. The study by Martin et al. (2017) also found that singletons born after eSET did not have a high risk of adverse neonatal outcomes (preterm birth $<37$ weeks, very preterm birth $<32$ weeks, low birth weight $<2500$ 
Table 3: Day-3 embryo transfer cycles outcomes

\begin{tabular}{|c|c|c|c|c|}
\hline Outcome & $\begin{array}{l}\text { eSET D3 } \\
(\mathrm{N}=132)\end{array}$ & $\begin{array}{l}\text { DET D3 } \\
(\mathrm{N}=140)\end{array}$ & $\begin{array}{c}\text { Relative risk } \\
\text { [95\%CI] } \\
\text { Absolute } \\
\text { differences } \\
(95 \% \mathrm{CI})^{*}\end{array}$ & P-value \\
\hline Age (years) & $29.9 \pm 3.1$ & $30.5 \pm 3.1$ & - & 0.16 \\
\hline $\operatorname{BMI}\left(\mathrm{kg} / \mathrm{m}^{2}\right)$ & $21.3 \pm 2.9$ & $21.3 \pm 2.4$ & - & 0.84 \\
\hline AMH (ng/ml) & $5.7 \pm 3.0$ & $5.1 \pm 3.5$ & - & 0.12 \\
\hline No. of oocytes retrieved (n) & $12.1 \pm 4.8$ & $13.6 \pm 4.4$ & - & 0.01 \\
\hline $\begin{array}{l}\text { No. of two-pronuclear fertilized } \\
\text { oocytes (n) }\end{array}$ & $11.7 \pm 4.9$ & $10.3 \pm 4.5$ & - & 0.02 \\
\hline No. of day-3 embryos (n) & $11.7 \pm 4.9$ & $9.0 \pm 4.6$ & - & $<0.001$ \\
\hline No. good day-3 embryos (n) & $7.2 \pm 3.2$ & $6.6 \pm 2.9$ & - & 0.07 \\
\hline Live birth - n (\%) & $30(22.7)$ & $55(39.3)$ & $0.45[0.27-0.77]$ & $<0.05$ \\
\hline$\beta$-hCG positive - n (\%) & $44(33.3)$ & $81(57.9)$ & $0.36[0.22-0.60]$ & $<0.001$ \\
\hline Implantation (\%) & $28.0 \pm 46.8$ & $30.3 \pm 34.8$ & $-2.3(-12.2,7.6)$ & 0.64 \\
\hline Clinical pregnacy - n (\%) & $36(27.2)$ & $68(48.6)$ & $0.40[0.24-0.66]$ & $<0.001$ \\
\hline Miscarriage $<12$ weeks $-\mathrm{n}(\%)$ & $4(3.0)$ & $8(5.7)$ & $0.52[0.15-0.75]$ & 0.28 \\
\hline Ectopic pregnacy - n (\%) & $2(1.5)$ & $4(2.9)$ & $0.52[0.09-2.90]$ & 0.45 \\
\hline $\begin{array}{l}\text { Ongoing pregnacy 12-week } \\
\text { gestation- } \mathrm{n}(\%)\end{array}$ & $32(24.2)$ & $59(42.1)$ & $0.44[0.26-0.74]$ & $<0.05$ \\
\hline Miscarriage $<20$ weeks- $\mathrm{n}(\%)$ & $2(1.5)$ & $2(1.4)$ & $1.06[0.15-7.65]$ & 0.95 \\
\hline Gestational age at birth (weeks) & $36.4 \pm 4.6$ & $36.5 \pm 4.1$ & $-0.1(-2.0,1.8)$ & 0.93 \\
\hline Multiple birth rate $-\mathrm{n}(\%)$ & $1(3.3)$ & $16(29.1)$ & $0.06[0.01-0.45]$ & $<0.001$ \\
\hline Birth weight of singleton (g) & $3086.7 \pm 325.1$ & $2898.2 \pm 598.3$ & $188.5(-9.6,386.5)$ & 0.06 \\
\hline Birth weight of twins (g) & $2000.0 \pm \mathrm{NA}$ & $2290.6 \pm 446.2$ & - & - \\
\hline
\end{tabular}

NA: not available

* Relative risk [95\% CI] were calculatedfor binary variables, Absolute differences (95\% CI) were calculated for continuous variables

g, and very low birth weight $<1500 \mathrm{~g}$ ), while singletons or twins born after DET had a higher risk compared with singletons due to natural conception ${ }^{25}$. The analysis of the data from three RCTs (publication dates of 2004, 2005, and 2006) also showed that the gestational age at birth and the birth weight of singletons born after the transfer of cleavage-stage embryos did not differ significantly versus a blastocyst transfer $^{30}$. eSET was found to be common in blastocysts rather than in cleavage-stage embryos due to the rates of clinical pregnancy. LBR after a single cleavagestage embryo transfer was found to be lower than that of a single blastocyst transfer ${ }^{16-18}$.

The strategy of a single day- 3 embryo transfer has been considered in our center in recent years ${ }^{16,18}$. Our study shows that the rates of $\beta$-hCG-positivity, implantation, clinical pregnancy, ongoing pregnancy, and LBR $(41.4 \%$ vs $22.7 \%, \mathrm{p}<0.001)$ in the eSET D5 group were significantly higher than those of the eSET D3 group (Table 5).

Currently, embryo transfer at the blastocyst stage is being promoted over cleavage-stage embryo transfer by IVF centers all over the world for many reasons. Firstly, blastocyst transfer optimizes the physiological synchronization between the endometrium and the embryo. Secondly, the gene expression in blastocysts is more complete, allowing for the self-selection of embryos with a higher implantation potential to be transferred. Thirdly, evidence-based medicine shows that blastocyst transfers have better clinical outcomes than the use of cleavage-stage embryos in some patient groups $17,31,32$. According to a systematic re- 
Table 4: Day-5 embryo transfer cycles outcomes

\begin{tabular}{|c|c|c|c|c|}
\hline Outcome & $\begin{array}{r}\text { eSET D5 } \\
(\mathrm{N}=278)\end{array}$ & $\begin{array}{c}\text { DET D5 } \\
(\mathrm{N}=269)\end{array}$ & $\begin{array}{c}\text { Relative risk }[95 \% \mathrm{CI}] \\
\text { Absolute } \\
\text { differences }(95 \%\end{array}$ & $P$-value \\
\hline Age (years) & $29.6 \pm 3.1$ & $29.8 \pm 3.1$ & - & 0.61 \\
\hline BMI $\left(\mathrm{kg} / \mathrm{m}^{2}\right)$ & $20.9 \pm 2.3$ & $21.1 \pm 2.6$ & - & 0.46 \\
\hline AMH (ng/ml) & $6.5 \pm 3.7$ & $6.7 \pm 3.8$ & - & 0.55 \\
\hline No. of oocytes retrieved (n) & $19.0 \pm 7.1$ & $17.8 \pm 6.7$ & - & 0.04 \\
\hline $\begin{array}{l}\text { No. of two-pronuclear fertilized } \\
\text { oocytes (n) }\end{array}$ & $17.8 \pm 7.3$ & $16.2 \pm 6.6$ & - & 0.02 \\
\hline No. of day-3 embryos (n) & $16.6 \pm 7.8$ & $15.3 \pm 6.9$ & - & 0.04 \\
\hline No. good day-3 embryos (n) & $9.0 \pm 3.7$ & $9.2 \pm 3.5$ & - & 0.53 \\
\hline Live birth - n (\%) & $115(41.4)$ & $115(42.8)$ & $0.94[0.67-1.33]$ & 0.74 \\
\hline$\beta$-hCG positive - n (\%) & $180(64.7)$ & $175(65.1)$ & $0.99[0.69-1.40]$ & 0.94 \\
\hline Implantation (\%) & $54.3 \pm 57.3$ & $34.2 \pm 37.2$ & $20.1(12.0,28.2)$ & $<0.001$ \\
\hline Clinical pregnacy - n (\%) & $140(50.4)$ & $139(51.7)$ & $0.95[0.68-1.33]$ & 0.76 \\
\hline Miscarriage < 12 weeks - n (\%) & $17(6.1)$ & $18(6.7)$ & $0.91[0.46-1.80]$ & 0.78 \\
\hline Ectopic pregnacy - n (\%) & $5(1.8)$ & $5(1.9)$ & $0.97[0.28-3.38]$ & 0.96 \\
\hline $\begin{array}{l}\text { Ongoing pregnacy 12-week } \\
\text { gestation- } \mathrm{n}(\%)\end{array}$ & $123(44.2)$ & $121(45.0)$ & $0.97[0.69-1.36]$ & 0.86 \\
\hline Miscarriage $<20$ weeks- $\mathrm{n}(\%)$ & $8(2.9)$ & $5(1.9)$ & $1.56[0.51-4.84]$ & 0.43 \\
\hline Gestational age at birth (weeks) & $35.8 \pm 4.8$ & $36.3 \pm 4.1$ & $-0.5(-1.7,0.6)$ & 0.34 \\
\hline Multiple birth rate - n (\%) & $11(9.6)$ & $44(38.3)$ & $0.21[0.11-0.42]$ & $<0.001$ \\
\hline Birth weight of singleton (g) & $2859.1 \pm 620.3$ & $2834.2 \pm 627.6$ & $24.9(-136.6,186.3)$ & 0.76 \\
\hline Birth weight of twins (g) & $2275.0 \pm 524.6$ & $2428.2 \pm 584.5$ & $-153.2(-535.6,229.2)$ & 0.41 \\
\hline
\end{tabular}

* Relative risk [95\%CI] were calculated for binary variables, Absolute differences (95\%CI) were calculated for continuous variable

view of 10 RCTs, there were no differences found in the rates of live birth, clinical pregnancies, and miscarriages between the blastocyst-stage transfer versus cleavage-stage embryo transfer ${ }^{31}$. According to a previous study on IVFMD, the findings show that cumulative LBR following a day-3 embryo transfer did not differ from that of a day-5 embryo transfer ${ }^{22}$. Once again, our study has demonstrated that the implantation rates of eSET D5 were the highest $(54.3 \% \pm$ $57.3 \%)$. This was significantly different compared to DET D5 (34.2\% \pm 37.2\%; Absolute difference: 20.1, 95\% CI: 12.0, $28.2 \mathrm{p}<0.001)$ and eSET D3 $(28.0 \% \pm$ 46.8\%; Absolute difference: 26.3 , 95\% CI: 15.8, 36.8; $\mathrm{p}<0.001)$.

However, extending the embryo culture to the blastocyst stage is heavily influenced by the external culture conditions. This means that the patient may face a higher risk of having no embryos to transfer ${ }^{33,34}$.
According to the analysis of ASRM, the rate of no blastocysts on day 5 was significantly higher compared to cleavage-stage embryos (8.9\% vs $2.8 \%$; 16 RCTs: OR 2.85; 95\% CI: $1.97-4.11)$. This was no different in good prognosis patients (9 RCTs: OR 1.50; $95 \%$ CI: $0.79-2.84)^{34}$. According to the reported data, the blastocyst formation rate was approximately 35 $-45 \%{ }^{35}$. The extended culture should only be performed when the IVF laboratory has a stable embryo culture system.

Blastocyst transfer also has a higher risk than cleavage-stage embryo transfer. These risks include preterm births, monozygotic twinning (MZT), and an imbalanced sex ratio (e.g. male offspring higher than female offspring) ${ }^{32-38}$. Furthermore, the use of the eSET D3 and eSET D5 strategy combination with selected embryos transferred by time-lapse morphokinetics showed no difference in terms of the pregnancy 


\begin{tabular}{|c|c|c|c|c|}
\hline Outcomes & $\begin{array}{l}\text { eSET D3 } \\
(\mathrm{N}=132)\end{array}$ & $\begin{array}{l}\text { eSET D5 } \\
(N=278)\end{array}$ & $\begin{array}{c}\text { Relative risk [95\% } \\
\text { CI] Absolute } \\
\text { differences }(95 \% \mathrm{CI})^{\star}\end{array}$ & P-value \\
\hline Age (years) & $29.9 \pm 3.1$ & $29.7 \pm 3.2$ & - & 0.40 \\
\hline BMI $\left(\mathrm{kg} / \mathrm{m}^{2}\right)$ & $21.3 \pm 2.9$ & $20.9 \pm 2.3$ & - & 0.1 \\
\hline $\mathrm{AMH}(\mathrm{ng} / \mathrm{ml})$ & $5.7 \pm 3.0$ & $6.5 \pm 3.7$ & - & 0.03 \\
\hline No. of oocytes retrieved (n) & $12.1 \pm 4.8$ & $19.0 \pm 7.1$ & - & $<0.001$ \\
\hline $\begin{array}{l}\text { No. of two-pronuclear fertilized } \\
\text { oocytes (n) }\end{array}$ & $11.7 \pm 4.9$ & $17.8 \pm 7.3$ & - & $<0.001$ \\
\hline No. of day-3 embryos (n) & $11.7 \pm 4.9$ & $16.6 \pm 7.8$ & - & $<0.001$ \\
\hline No. good day-3 embryos (n) & $7.2 \pm 3.1$ & $9.0 \pm 3.7$ & - & $<0.001$ \\
\hline Live birth - n (\%) & $30(22.7)$ & $115(41.4)$ & $0.42[0.26-0.67]$ & $<0.001$ \\
\hline$\beta$-hCG positive - n (\%) & $44(33.3)$ & $180(64.7)$ & $0.27[0.18-0.42]$ & $<0.001$ \\
\hline Implantation (\%) & $28.0 \pm 46.8$ & $54.33 \pm 57.3$ & $-26.3(-36.8,-15.8)$ & $<0.001$ \\
\hline Clinical pregnacy $-\mathrm{n}(\%)$ & $36(27.2)$ & $140(50.4)$ & $0.27[0.18-0.42]$ & $<0.001$ \\
\hline Miscarriage $<12$ weeks $-\mathrm{n}(\%)$ & $4(3.0)$ & $17(6.1)$ & $0.48[0.16-1.46]$ & 0.19 \\
\hline Ectopic pregnacy - n (\%) & $2(1.5)$ & $5(1.8)$ & $0.84[0.16-4.39]$ & 0.84 \\
\hline $\begin{array}{l}\text { Ongoing pregnacy } 12 \text {-week ges- } \\
\text { tation - } \mathrm{n}(\%)\end{array}$ & $32(24.2)$ & $123(44.2)$ & $0.40[0.25-0.64]$ & $<0.001$ \\
\hline Miscarriage $<20$ weeks- $\mathrm{n}(\%)$ & $2(1.5)$ & $8(2.9)$ & $0.52[0.11-2.48]$ & 0.40 \\
\hline Gestational age at birth (weeks) & $36.4 \pm 4.6$ & $35.8 \pm 4.8$ & $0.6(-1.2,2.4)$ & 0.45 \\
\hline Multiple birth rate $-\mathrm{n}(\%)$ & $1(3.3)$ & $11(9.6)$ & $0.19[0.02-1.45]$ & 0.07 \\
\hline Birth weight of singleton (g) & $3086.7 \pm 325.1$ & $2859.1 \pm 620.3$ & $227.6(63.3,391.9)$ & 0.01 \\
\hline Birth weight of twins (g) & $2000.0 \pm N A$ & $2275.0 \pm 524.6$ & - & - \\
\hline
\end{tabular}

NA: not available

* Relative risk [95\% CI] were calculated for binary variables, Absolute differences ( $95 \% \mathrm{CI}$ ) were calculated for continuous variable

outcomes (such as implantation rate, early ectopic births, and live births) and neonatal outcomes (such as preterm births, gestational age, birth height, and birth weight). The rate of MZT in the eSET D5 group was significantly higher than that of eSET D3 (6.98\% vs $0.00 \%, \mathrm{p}<0.05)^{39}$. Our study showed that when performing eSET, there was also MZT. The multiple birth rates of eSET D3 were lower but not statistically significant compared to those of eSET D5 (3.3\% $(1 / 30)$ versus $9.6 \%(11 / 115)$, respectively; $R R=0.19$, $95 \%$ CI: $0.02-1.45, \mathrm{p}=0.07)$. This means that eSET D3 can be an option for embryo transfer to minimize monozygotic twins. The results of this study provide scientific evidence for doctors and embryologists to better consult with good prognosis patients on the strategies of eSET versus DET at the cleavage-stage embryo or blastocyst stage.
The limitations of this study included its retrospective design, which only focused on analysis of pregnancy and neonatal outcomes in one patient group (good prognosis patients). Further studies with larger sample sizes and a prospective design will be needed to increase the reliability of the efficacy of the eSET strategy in different patient groups.

\section{CONCLUSIONS}

Elective single embryo transfer in good prognosis patients should be a choice to minimize the risk of multiple pregnancies while achieving acceptable live birth and neonatal outcomes. The strategy of an elective single blastocyst transfer for good prognosis patients was an optimal option that ensured a balance between live birth outcomes and the minimal risk of multiple pregnancies. Elective single day- 3 embryo transfer had the lowest live birth rate and minimized the 
risk of multiple pregnancies. The doctor or embryologist should consult the good prognosis patients about the efficiency and safety of each embryo transfer strategy. The results of this study can provide scientific evidence to support controlling infertility treatment through specific embryo transfer strategies in Vietnamese good prognostic IVF patients.

\section{ABBREVIATIONS}

AMH: Anti-Muller hormone

ASRM: American Society for Reproductive Medicine BMI: Body mass index

D3: Day 3

D5: Day 5

DET: Double embryo transfer

eSET: elective single embryo transfer

FET: Frozen embryo transfer

FSH: Follical stimulating hormone

ICM: Inner cell mass

ICSI: Intracytoplasmic sperm injection

IVF: In vitro fertilization

IVM: In vitro maturation

LBRs: Live birth rates

MBRs: Multiple brith rates

OHSS: Ovarian hyperstimulation syndrome

MPR: Multiple pregnancy rates

PCOS: Polycystic ovary syndrome

SART: Society for Assisted Reproductive Technology

\section{ACKNOWLEDGMENTS}

This study was performed at IVFMD PN-My Duc Phu Nhuan Hospital, IVFMD-My Duc Hospital. The authors would like to thank the Board of Directors for their support. We are also thankful to our colleagues from IVFMD PN who positively assisted in completing this study.

\section{AUTHOR'S CONTRIBUTIONS}

All authors read and approved the final manuscript.THLT wrote the manuscript. NHD re-vised the manuscript. DQV planned and designed the experiments. DTL and PHH collected the data. NTL collected and analyzed the data. NTTH supervised the study and finalized the manuscript. All authors read and confirmed the publication of the article.

\section{FUNDING}

None.

\section{AVAILABILITY OF DATA AND MATERIALS}

Data and materials used and/or analyzed during the current study are available from the corresponding author on reasonable request.

\section{ETHICS APPROVAL AND CONSENT TO PARTICIPATE}

This study was conducted in accordance with the amended Declaration of Helsinki. The institutional review board approved the study, and all participants provided written informed consent.

\section{CONSENT FOR PUBLICATION}

Not applicable.

\section{COMPETING INTERESTS}

The authors declare that they have no competing interests.

\section{REFERENCES}

1. Gleicher N, Kushnir VA, Barad DH. Worldwide decline of IVF birth rates and its probable causes. Hum Reprod Open. 2019;2019(3). PMID: 31406934. Available from: 10.1093/ hropen/hoz017.

2. Sunderam S, Kissin DM, Crawford SB, Folger SG, Jamieson DJ, Warner L. Assisted Reproductive Technology Surveillance United States, 2014. MMWR Surveill Summ. 2017;66(6):1-24. PMID: 28182605. Available from: 10.15585/mmwr.ss6606a1.

3. Sunderam S, Kissin DM, Zhang Y, Folger SG, Boulet SL, Warner L. Assisted Reproductive Technology Surveillance - United States, 2016. MMWR Surveill Summ. 2019;68(4):1-23. PMID: 31022165. Available from: 10.15585/mmwr.ss6804al.

4. Santana DS, Cecatti JG, Surita FG, Silveira C, Costa ML, Souza $J P$, et al. Twin Pregnancy and Severe Maternal Outcomes: The World Health Organization Multicountry Survey on Maternal and Newborn Health. Obstet Gynecol. 2016;127(4):63141. PMID: 26959199. Available from: 10.1097/AOG. 0000000000001338.

5. Eapen A, Ryan GL, Eyck PT, Voorhis BJV. Current evidence supporting a goal of singletons: a review of maternal and perinatal outcomes associated with twin versus singleton pregnancies after in vitro fertilization and intracytoplasmic sperm injection. Fertil Steril. 2020;114(4):690-714. PMID: 33040979. Available from: 10.1016/j.fertnstert.2020.08.1423.

6. Maheshwari A, Pandey S, Raja EA, Shetty A, Hamilton M, Bhattacharya $S$. Is frozen embryo transfer better for mothers and babies? Can cumulative meta-analysis provide a definitive answer? Hum Reprod Update. 2018;24(1):35-58. PMID: 29155965. Available from: 10.1093/humupd/dmx031.

7. Tremellen K, Wilkinson D, Savulescu J. Is mandating elective single embryo transfer ethically justifiable in young women? Reprod Biomed Soc Online. 2016;1(2):81-7. PMID: 29911189. Available from: 10.1016/j.rbms.2016.02.001.

8. Harbottle S, Hughes C, Cutting R, Roberts S, Brison D, \&amp; The (ACE) British Fertility Society (BFS) AOCE. Elective Single Embryo Transfer: an update to UK Best Practice Guidelines. Hum Fertil (Camb). 2015;18(3):165-83. PMID: 26391438. Available from: 10.3109/14647273.2015.1083144.

9. Lee AM, Connell MT, Csokmay JM, Styer AK. Elective single embryo transfer- the power of one. Contracept Reprod Med. 2016;1(1):11. PMID: 29201400. Available from: 10.1186/ s40834-016-0023-4.

10. Niederberger C, Pellicer A, Cohen J, Gardner DK, Palermo GD, O'Neill CL. Forty years of IVF. Fertil Steril. 2018;110(2). PMID: 30053940. Available from: 10.1016/j.fertnstert.2018.06.005. 
11. Penzias A, Bendikson K, Butts S, Coutifaris C, Fossum G, Falcone $T$, et al. Guidance on the limits to the number of embryos to transfer: a committee opinion. Fertil Steril. 2017;107(4):901-3. PMID: 28292618. Available from: 10.1016/ j.fertnstert.2017.02.107.

12. Farquhar $C$. Avoiding multiple pregnancies in assisted reproductive technologies: transferring one embryo at a time should be the norm. Fertil Steril. 2020;114(4):671-2. PMID: 33040978. Available from: 10.1016/j.fertnstert.2020.08.1404.

13. Adamson GD, Norman RJ. Why are multiple pregnancy rates and single embryo transfer rates so different globally, and what do we do about it? Fertil Steril. 2020;114(4):680-9. PMID: 33010940. Available from: 10.1016/j.fertnstert.2020.09.003.

14. of the Society for Assisted Reproductive Technology PC, the American Society for Reproductive Medicine. Guidelines on the number of embryos transferred. Fertil Steril. 2004;82:1-2. PMID: 15363679. Available from: 10.1016/j.fertnstert.2004.07. 937.

15. Mancuso AC, Boulet SL, Duran E, Munch E, Kissin DM, Voorhis BJV. Elective single embryo transfer in women less than age 38 years reduces multiple birth rates, but not live birth rates, in United States fertility clinics. Fertil Steril. 2016;106(5):110714. PMID: 27376458. Available from: 10.1016/j.fertnstert.2016. 06.017 .

16. Papanikolaou EG, Camus M, Kolibianakis EM, Landuyt LV, Steirteghem AV, Devroey P. In vitro fertilization with single blastocyst-stage versus single cleavage-stage embryos. N Engl J Med. 2006;354(11):1139-46. PMID: 16540614. Available from: 10.1056/NEJMoa053524.

17. Glujovsky D, Farquhar C, Retamar AMQ, Sedo CRA, Blake D. Cleavage stage versus blastocyst stage embryo transfer in assisted reproductive technology; 2016. Available from: 10 . 1002/14651858.CD002118.pub5.

18. Mersereau J, Stanhiser J, Coddington C, Jones T, Luke B, Brown MB. Patient and cycle characteristics predicting high pregnancy rates with single-embryo transfer: an analysis of the Society for Assisted Reproductive Technology outcomes between 2004 and 2013. Fertil Steril. 2017;108(5):750-6. PMID: 28923285. Available from: 10.1016/j.fertnstert.2017.07.1167.

19. Friedman BE, Davis LB, Lathi RB, Westphal LM, Baker VL, Milki AA. Age-related successwith elective single versus double blastocyst transfer. ISRN Obstet Gynecol. 2011;2011:656204. PMID: 22191047. Available from: 10.5402/2011/656204.

20. Wintner EM, Hershko-Klement A, Tzadikevitch $K$, Ghetler $Y$, Gonen $\mathrm{O}$, Wintner $\mathrm{O}$. Does the transfer of a poor quality embryo together with a good quality embryo affect the In Vitro Fertilization (IVF) outcome? J Ovarian Res. 2017;10(1):2. PMID: 28086935. Available from: 10.1186/s13048-016-0297-9.

21. Vuong LN, Dang VQ, Ho TM, Huynh BG, Ha DT, Pham TD. IVF transfer of fresh or frozen embryos in women without polycystic ovaries. N Engl J Med. 2018;378(2):137-47. PMID: 29320655. Available from: 10.1097/01.ogx.0000532004.69352. 03.

22. Bich NN, et al. Tî lệ trẻ sinh sống cộng dồn chu kỳ chuyển phôi trữ giai đoạn phôi phân chia ngày 3 so với giai đoạn phôi nang: một nghiên cứu đoàn hệ hồi cứu. Y học Thực hành (In Vietnamese). 2018;.

23. Phuong LT, Thuc VN, Quan PT, Anh LH, Vinh DQ, Huyen NT. Selecting euploid embryo for transfer by preimplantation genetic testing for aneuploidy improved clinical outcomes in patients with advanced maternal age. Biomed Res Ther. 2019;6(12):3541-9. Available from: 10.15419/bmrat.v6i12.581.

24. WHO. Chapter 5. Sperm preparation techniques. in WHO Laboratory Manual for the Examination and Processing of Human Semen (5th edition). 2010;17:161-168.

25. Eum JH, Park JK, Kim SY, Paek SK, Seok HH, Chang EM. Clinical outcomes of single versus double blastocyst transfer in fresh and vitrified-warmed cycles. Clin Exp Reprod Med. 2016;43(3):164-8. PMID: 27689039. Available from: 10.5653/ cerm.2016.43.3.164.

26. Racca A, Drakopoulos P, Landuyt LV, Willem C, Santos-Ribeiro $\mathrm{S}$, Tournaye $\mathrm{H}$. Single and double embryo transfer provide similar live birth rates in frozen cycles. Gynecol Endocrinol. 2020;36(9):824-8. PMID: 32124642. Available from: 10.1080/ 09513590.2020 .1712697$.

27. Bos-Mikich A, Michels MS, Dutra CG, Oliveira NP, Ferreira MO, Aquino DC. The impact of age on blastocyst scoring after single and double embryo transfers. JBRA Assist Reprod. 2016;20(1):27-32. PMID: 27203303. Available from: 10.5935/ 1518-0557.20160007.

28. Freeman MR, Hinds MS, Howard KG, Howard JM, Hill GA. Guidance for elective single-embryo transfer should be applied to frozen embryo transfer cycles. J Assist Reprod Genet. 2019;36(5):939-46. PMID: 30859416. Available from: 10.1007/ s10815-019-01433-w.

29. Martin AS, Chang J, Zhang Y, Kawwass JF, Boulet SL, McKane $P$, et al. Perinatal outcomes among singletons after assisted reproductive technology with single-embryo or double-embryo transfer versus no assisted reproductive technology. Fertil Steril. 2017;107(4):954-60. PMID: 28292615. Available from: 10.1016/j.fertnstert.2017.01.024.

30. Vos AD, Santos-Ribeiro SD, Tournaye H, Verheyen G. Birthweight of singletons born after blastocyst-stage or cleavagestage transfer: analysis of a data set from three randomized controlled trials. J Assist Reprod Genet. 2020;37(1):127-32. PMID: 31836942 . Available from: 10.1007/s10815-019-016414.

31. Martins WP, Nastri CO, Rienzi L, van der Poel SZ, Gracia C, Racowsky C. Blastocyst vs cleavage-stage embryo transfer: systematic review and meta-analysis of reproductive outcomes. Ultrasound Obstet Gynecol. 2017;49(5):583-91. PMID: 27731533. Available from: 10.1002/uog.17327.

32. Maheshwari A, Hamilton M, Bhattacharya S. Should we be promoting embryo transfer at blastocyst stage? Reprod Biomed Online. 2016;32(2):142-6. PMID: 26673100. Available from: 10.1016/j.rbmo.2015.09.016.

33. Glujovsky D, Farquhar C. Cleavage-stage or blastocyst transfer: what are the benefits and harms? Fertil Steril. 2016;106(2):244-50. PMID: 27421614. Available from: 10. 1016/j.fertnstert.2016.06.029.

34. of the American Society for Reproductive Medicine PC, the Society for Assisted Reproductive Technology. Blastocyst culture and transfer in clinical-assisted reproduction: a committee opinion. Fertil Steril. 2013;99(3):667-72. PMID: 23714439. Available from: 10.1016/j.fertnstert.2013.01.087.

35. Sepúlveda SJ, Portella JR, Noriega LP, Escudero EL, Noriega LH. Extended culture up to the blastocyst stage: a strategy to avoid multiple pregnancies in assisted reproductive technologies. Biol Res. 2011;44(2):195-9. PMID: 22513423. Available from: $10.4067 /$ S0716-97602011000200012.

36. Hattori H, Kitamura A, Takahashi F, Kobayashi N, Sato A, Miyauchi $\mathrm{N}$, et al. The risk of secondary sex ratio imbalance and increased monozygotic twinning after blastocyst transfer: data from the Japan Environment and Children's Study. Reprod Biol Endocrinol. 2019;17(1):27. PMID: 30795788. Available from: 10.1186/s12958-019-0471-1.

37. MacKenna A, Schwarze JE, Crosby J, Zegers-Hochschild F. Factors associated with embryo splitting and clinical outcome of monozygotic twins in pregnancies after IVF and ICSI. Hum Reprod Open. 2020;2020(1). PMID: 32432173. Available from: 10.1093/hropen/hoaa024.

38. Busnelli A, Dallagiovanna C, Reschini M, Paffoni A, Fedele L, Somigliana E. Risk factors for monozygotic twinning after in vitro fertilization: a systematic review and meta-analysis. Fertil Steril. 2019;111(2):302-17. PMID: 30691632. Available from: 10.1016/j.fertnstert.2018.10.025.

39. Wang S, Chen L, Fang J, Jiang W, Zhang N. Comparison of the pregnancy and obstetric outcomes between single cleavage-stage embryo transfer and single blastocyst transfer by time-lapse selection of embryos. Gynecol Endocrinol. 2019:35(9):792-5. PMID: 30971141. Available from: 10.1080/ 09513590.2019 .1594762 . 
Ready to submit your manuscript? Choose Biomedpress and benefit from:

- Fast, convenient online submission

- Through peer-review by experienced researchers

- Rapid publication on acceptance

- Free of charge (without publication fees)

Learn more http://www.biomedpress.org/journals/

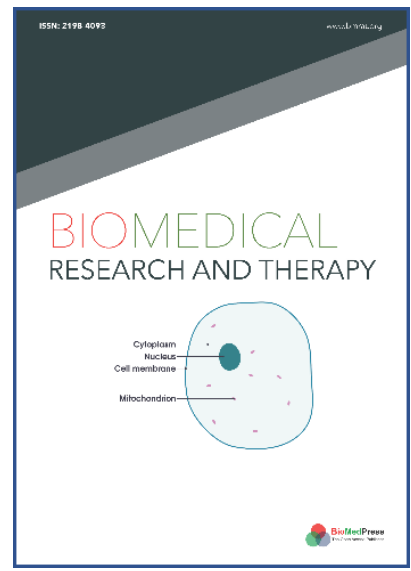

\title{
Biomedical Research and Therapy
}

Indexed: Web of Science (ESCl), Embase, Google Scholar

Journal Citation Indicator (2020): 0.16

Acceptance Rate (2020): 54.32\%

Article Publishing Charge: Free

Submission to first editorial decision: 27 days

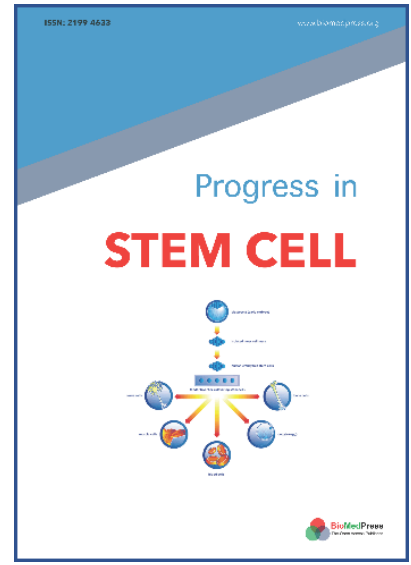

\section{Progress in Stem Cell}

Indexed: Embase, Google Scholar

Acceptance Rate (2020): 78.19\%

Article Publishing Charge: Free

Submission to first editorial decision: 19 days

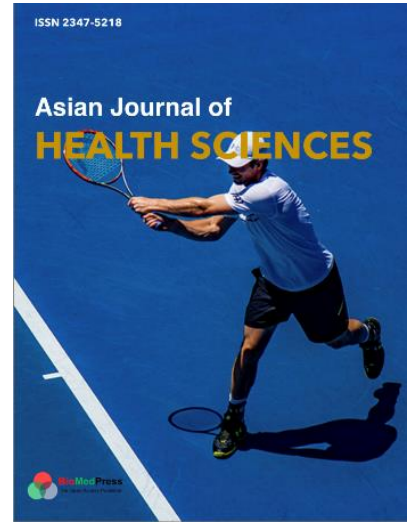

\author{
Asian Journal of Health Sciences \\ Indexed: Google Scholar \\ Acceptance Rate (2020): 72.89\% \\ Article Publishing Charge: Free \\ Submission to first editorial decision: 16.5 days
}

